\section{New academy focuses on bone and tissue regeneration}

The Bone, Biomaterials \& Beyond (BBB) Academy is a new organisation focusing on bone and tissue regeneration.

BBB President Professor Antonio

Barone and International Chairman Professor Ulf Nannmark have stated that the goal of the academy is to share and develop the experiences of an important group of researchers and clinicians in the regenerative field. According to Nannmark, in the last ten years, the core group of the BBB have developed several research protocols to prove the efficacy of xenogeneic dual-phase biomaterials and to define effective and predictable surgical techniques to associate with these materials.

The collaboration between a variety of professionals over the years in experimental and clinical research has led to a number of scientific articles and led to the publication of the 2014 book Bone, Biomaterials \& Beyond. The book has since been translated into several languages and, according to the $\mathrm{BBB}$, was a major starting point for the academy itself.

According to the group, during the last ten years a revolution has occurred both in the regenerative biomaterials field and in the development of new surgical techniques. Owing to this, there has been a significant improvement in the therapeutic options available for dentists and oral surgeons, allowing excellent clinical results that were achievable in the past only with autogenous grafts.

When commenting on the reasoning behind forming such an organisation, the $\mathrm{BBB}$ stated that it believes that regenerative procedures for bone and soft tissue should be developed and performed with materials that can be biologically integrated into human tissue. This should then be brought to a wider professional base through official international organisations such as the BBB.

The first BBB Academy Guided Bone Regeneration Symposium will be held on 19 May 2018 at Lake Maggiore, Italy.

For more information email info@ bbb.academy or visit www.bbb.academy.

\section{Business experts to hold workshop}

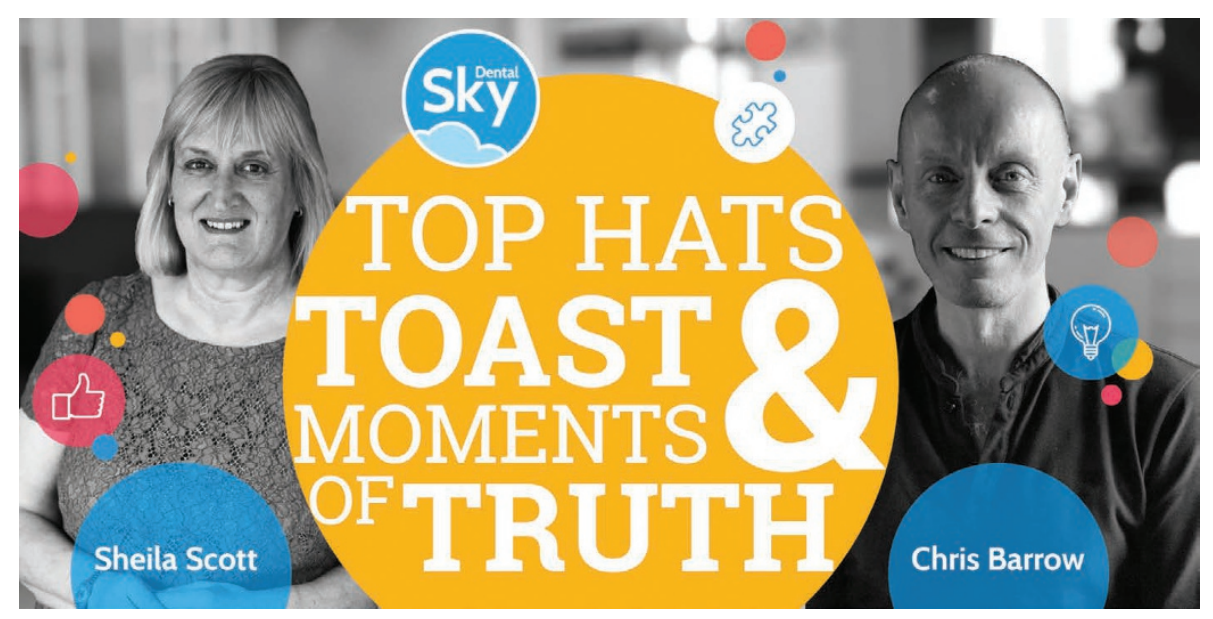

Dental Sky is sponsoring a practical and engaging workshop from dental business experts, Chris Barrow and Sheila Scott. They will help delegates understand collaborative visualisation and how it can generate new ideas and benefit you and your team.

During the workshop you'll discover an efficient approach to team discussion and problem-solving that can be applied to lots of different scenarios in your practice. You'll explore the importance of understanding that people think in different ways and how this can enhance teamwork back in practice.

The day will enable you to develop your existing patient experience and, as a team, move it onto the next level. Every member of the team will play an important part... but don't worry there won't be any role play!

This event is hosted in one of three locations: The Luton Hoo Hotel (17 April), the Village Hotel Dudley (20 June) and the Village Hotel Edinburgh (29 November).

The workshop will be a full-day event from 9.00 am to approximately $5.00 \mathrm{pm}$ and attendees will earn five hours' verifiable CPD. The cost per workshop is $£ 95$ and includes lunch and refreshments throughout the day. To book your place, contact ruby. booker@dentalsky.com.

\section{A game-changer in implant dentistry}

Implant dentists and dental technicians are reacting enthusiastically to the latest technological advance from Anthogyr - Axiom Multi Level. This user-friendly concept offers a unique range of surgical and prosthetic options for every indication, according to aesthetic and clinical requirements. It provides flexible, time-saving and prosthetically driven implant placement for single tooth, short-span bridge and full arch restorations.

Axiom Multi Level helps clinicians achieve optimal crestal bone stability and predictable aesthetic results, for both boneand tissue-level placement. The morse taper design helps to avoid bone loss, providing a tight seal, narrow exit and firm fit.

The inLink connection is completely integrated within the Simeda CAD/CAM prosthesis. It requires no manipulation or transport of screws, and accelerates the workflow for same-day teeth.

It is now possible to combine the use of Axiom TL (Tissue Level) and Axiom BL (Bone Level) implants in the same prosthesis. The system compensates for extreme divergence of implant axes with no need for an intermediary abutment. It offers angulated access of screw channels to $25^{\circ}$ on every inLink connection.

For more information call 08000857119 or visit www.anthogyr.co.uk. 